\title{
Unexpected Arabinosylation after Humanization of Plant Protein $N$-Glycosylation
}

\section{OPEN ACCESS}

Edited by:

Johannes Felix Buyel, Fraunhofer Society (FHG), Germany

Reviewed by:

Takao Ohashi,

Setsunan University, Japan Luisa Bortesi,

Maastricht University, Netherlands

${ }^{*}$ Correspondence:

Eva L. Decker

eva.decker@biologie.uni-freiburg.de

tORCID:

Lennard L. Bohlender orcid.org/0000-0002-4599-7807

Juliana Parsons orcid.org/0000-0001-6261-2342

Sebastian N. W. Hoernstein orcid.org/0000-0002-2095-689X

Ralf Reski

orcid.org/0000-0002-5496-6711

Eva L. Decker

orcid.org/0000-0002-9151-1361

Specialty section:

This article was submitted to Industrial Biotechnology,

a section of the journal

Frontiers in Bioengineering and Biotechnology

Received: 17 December 2021 Accepted: 28 January 2022

Published: 18 February 2022

Citation:

Bohlender LL, Parsons J, Hoernstein SNW, Bangert N,

Rodríguez-Jahnke F, Reski $R$ and

Decker EL (2022) Unexpected Arabinosylation after Humanization of

Plant Protein N-Glycosylation.

Front. Bioeng. Biotechnol. 10:838365.

doi: 10.3389/fbioe.2022.838365
Lennard L. Bohlender ${ }^{1 \dagger}$, Juliana Parsons ${ }^{1 \dagger}$, Sebastian N. W. Hoernstein ${ }^{1 \dagger}$, Nina Bangert ${ }^{1}$, Fernando Rodríguez-Jahnke ${ }^{1,2}$, Ralf Reski ${ }^{1,2,3 \dagger}$ and Eva L. Decker ${ }^{1 \star \dagger}$

${ }^{1}$ Plant Biotechnology, Faculty of Biology, University of Freiburg, Freiburg, Germany, ${ }^{2}$ Spemann Graduate School of Biology and Medicine (SGBM), University of Freiburg, Freiburg, Germany, ${ }^{3}$ Signalling Research Centres BIOSS and CIBSS, University of Freiburg, Freiburg, Germany

As biopharmaceuticals, recombinant proteins have become indispensable tools in medicine. An increasing demand, not only in quantity but also in diversity, drives the constant development and improvement of production platforms. The $\mathrm{N}$-glycosylation pattern on biopharmaceuticals plays an important role in activity, serum half-life and immunogenicity. Therefore, production platforms with tailored protein $\mathrm{N}$-glycosylation are of great interest. Plant-based systems have already demonstrated their potential to produce pharmaceutically relevant recombinant proteins, although their $\mathrm{N}$-glycan patterns differ from those in humans. Plants have shown great plasticity towards the manipulation of their glycosylation machinery, and some have already been glycoengineered in order to avoid the attachment of plant-typical, putatively immunogenic sugar residues. This resulted in complex-type $N$-glycans with a core structure identical to the human one. Compared to humans, plants lack the ability to elongate these $N$-glycans with $\beta 1,4$-linked galactoses and terminal sialic acids. However, these modifications, which require the activity of several mammalian enzymes, have already been achieved for Nicotiana benthamiana and the moss Physcomitrella. Here, we present the first step towards sialylation of recombinant glycoproteins in Physcomitrella, human $\beta 1,4$-linked terminal $N$-glycan galactosylation, which was achieved by the introduction of a chimeric $\beta 1,4$-galactosyltransferase (FTGT). This chimeric enzyme consists of the moss a 1,4fucosyltransferase transmembrane domain, fused to the catalytic domain of the human $\beta 1,4$-galactosyltransferase. Stable FTGT expression led to the desired $\beta 1,4$ galactosylation. However, additional pentoses of unknown identity were also observed. The nature of these pentoses was subsequently determined by Western blot and enzymatic digestion followed by mass spectrometric analysis and resulted in their identification as $\alpha$-linked arabinoses. Since a pentosylation of $\beta 1,4$-galactosylated $\mathrm{N}$-glycans was reported earlier, e.g., on recombinant human erythropoietin produced in glyco-engineered Nicotiana tabacum, this phenomenon is of a more general importance for plant-based production platforms. Arabinoses, which are absent in humans, may prevent the full humanization of plant-derived products. Therefore, the identification of these pentoses as arabinoses is important as it creates the basis for their abolishment to ensure the production of safe biopharmaceuticals in plant-based systems. 


\begin{abstract}
Keywords: glyco-optimization, $\boldsymbol{N}$-glycan-humanization, glyco-engineering, Physcomitrella (Physcomitrium patens), $N$-glycan-pentosylation, plant-made recombinant biopharmaceuticals, $\beta 1,4$-galactosylation, plant-made pharmaceuticals (PMP)
\end{abstract}

\section{INTRODUCTION}

Recombinant protein biopharmaceuticals are highly effective and specific, and therefore essential in the area of healthcare. The advancement of biotechnology made their production feasible, their share in the market has grown steadily in the last decades and is predicted to keep growing (Facts and Figures 2021: The Pharmaceutical Industry and Global Health; Walsh, 2018). The production of high-quality therapeutic proteins is still a complex process. For this the biosynthesis machinery from cells is required, and the choice of the production platform is highly associated with the product's requirements and quality (Tripathi and Shrivastava, 2019). Proteins are frequently posttranslationally modified. Particularly, protein $N$-glycosylation, a very common post-translational modification (PTM) in most eukaryotes, is of great importance as most protein biopharmaceuticals need a correct glycosylation to achieve the desired therapeutic efficacy (Solá and Griebenow, 2010) and to prevent immunogenic effects by the pharmaceutical (Zhou and Qiu, 2019). Mammalian (esp. Chinese Hamster Ovary (CHO)) cell lines, have dominated the recombinant biologics industry since the 1990s, largely because their PTMs resemble human ones (Walsh, 2018; Tripathi and Shrivastava, 2019). However, high production costs of these systems and the increasing demand of newly designed protein therapeutics, driven by the growing knowledge of molecular mechanisms of diseases, reveal the need for alternative platforms for tailored production. The current COVID-19 pandemic highlights particularly the urgent need to expand the production capacities for vaccines, diagnostic reagents and therapeutical proteins, such as neutralizing antibodies. Plant-based production of biopharmaceuticals offers an interesting alternative. For this, plants combine several advantageous properties like their ability to produce, fold and post-translationally modify complex proteins, a high range of scalability combined with cost-effective cultivation and the lack of human pathogens which provides inherent safe products (Buyel, 2019). Currently, one plant-produced recombinant therapeutic is on the market (Elelyso, a $\beta$ glucocerebrosidase for the treatment of Morbus Gaucher, Grabowski et al., 2014) and many promising plant-made biopharmaceuticals are in clinical trials. Among them are the HIV-neutralizing human monoclonal antibody 2 G12 produced in Nicotiana tabacum ( $\mathrm{Ma}$ et al., 2015), the Nicotiana benthamiana-derived virus-like particles as candidate vaccines against influenza, dengue fever or COVID-19, respectively (Ward et al., 2020, 2021; Ponndorf et al., 2021) or a-galactosidase for enzyme replacement therapy in Morbus Fabry treatment produced in the moss Physcomitrella (Shen et al., 2016; Hennermann et al., 2019). Physcomitrella provides several beneficial features for biopharmaceutical production (reviewed in Decker and Reski, 2020): its high rate of somatic homologous recombination enables easy genome engineering (e.g., Strepp et al., 1998; Wiedemann et al., 2018), it is able to produce complex recombinant human proteins and multi-level synthetic complement regulators (Reski et al., 2015; Michelfelder et al., 2017; Top et al., 2019; Ruiz-Molina et al., 2021), can be cultivated under Good Manufacturing Practice (GMP) conditions in suspensions with volumes up to $500 \mathrm{~L}$ in photobioreactors (Reski et al., 2018). The promising biopharmaceutical candidates mentioned above demonstrate the potential of plant-based systems in this field. All the plantderived biopharmaceuticals approved or in advanced clinical trials have in common, that their efficacy is not impaired by the lack of mammalian-typical $N$-glycosylation patterns, which differ from those produced in plants. The early processing of $\mathrm{N}$-glycans in plants and mammals is conserved, while their maturation in the Golgi apparatus differs (Gomord et al., 2010). Plant and human $N$-glycans share the identical heptasaccharide GlcNAc $\mathrm{Man}_{3} \mathrm{GlcNAc}_{2}$ (GnGn, Figure 1) diantennary complex-type core structure, while fucosylation of the Asn-linked $\mathrm{N}$-acetylglucosamine (GlcNAc) is a1,3-linked in plants and a1,6-linked in humans. In humans though not in plants, the GnGn core is extended via $\beta 1,4$-linked galactose, which is often terminally capped with $\alpha 2,6$-linked sialic acid. In plants, the $\mathrm{GnGn}$ core is substituted with a $\beta 1,2$-linked xylose, a sugar not produced in humans, and it is terminally extended by $\beta 1,3$-linked galactose and $\alpha 1,4$-linked fucose, both linked to the outer GlcNAc residues, forming the trisaccharidic Lewis A $\left(\mathrm{Le}^{\mathrm{a}}\right)$ epitope. This epitope as well as the plant-specific $\beta 1,2$-attached xylose and the $\alpha 1,3$-attached fucose have been associated with antibody formation in humans (Fitchette et al., 1999; Wilson et al., 2001). Antibodies recognizing a therapeutic protein can affect its efficacy by altering the pharmacokinetics and pharmacodynamics, and represent an additional safety risk (Tourdot and Hickling, 2019). Therefore, to avoid potential immunogenicity of plant-made therapeutical proteins, plantspecific $N$-glycan residues have already been tackled. Plantspecific $N$-glycan xylosylation and fucosylation were eliminated in several plant-based systems by knockout (KO) or downregulation of the genes encoding the respective xylosyltransferases (XT) and fucosyltransferases (FT) (Koprivova et al., 2004; Strasser et al., 2004, 2008; Cox et al., 2006; Sourrouille et al., 2008; Shin et al., 2011; Hanania et al., 2017; Mercx et al., 2017; Jansing et al., 2018). Additionally, Le epitope formation was abolished in Physcomitrella by knockout of the $\beta 1,3$-galactosyltransferase 1 (GalT1) encoding gene (Parsons et al., 2012). The triple KO of $x t, f t$ and galt 1 in Physcomitrella resulted in an outstanding $N$-glycan homogeneity, with a strongly predominant GnGn glycosylation pattern (Parsons et al., 2012). This provides a suitable platform for the further glyco-optimization, comprising $\beta 1,4$-galactosylation and sialylation.

The impact of terminal $\mathrm{N}$-glycan residues on efficacy and functional role of protein therapeutics has been extensively 


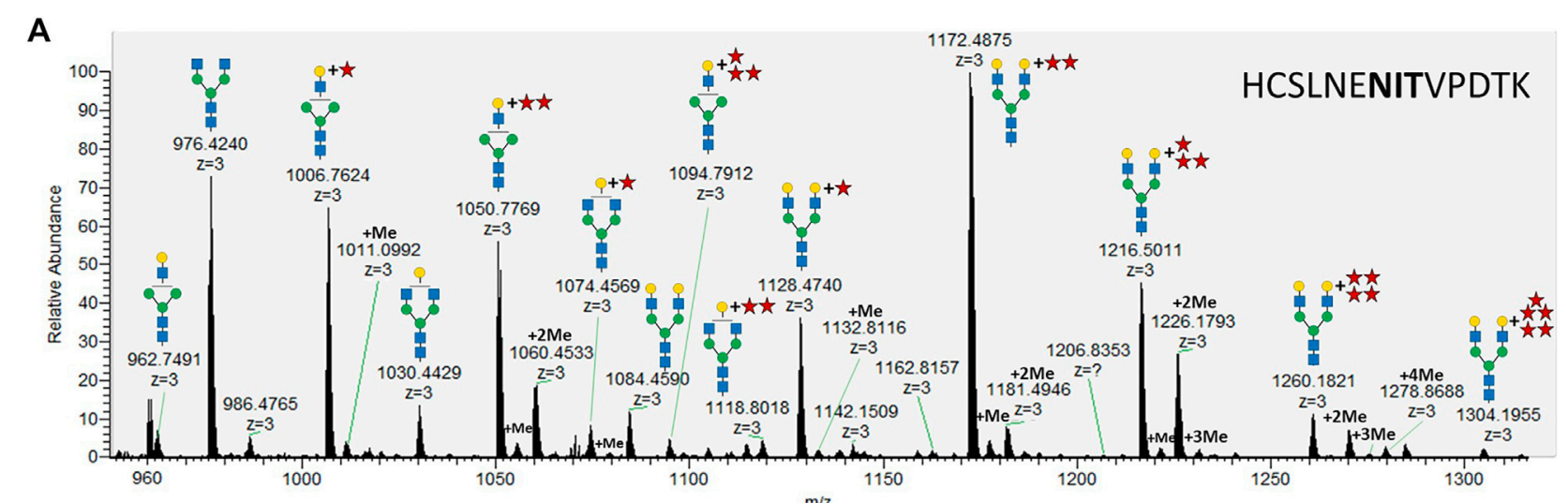

B

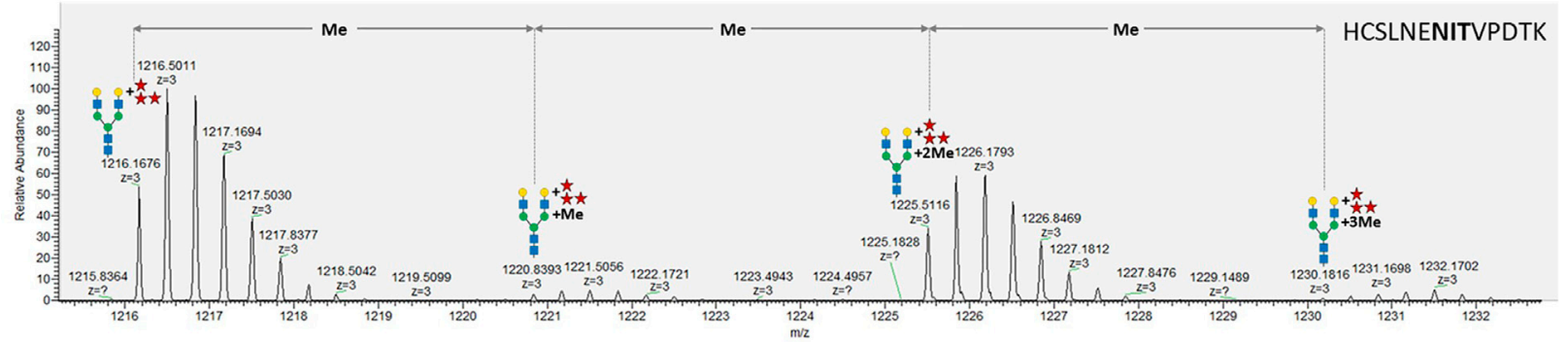

C

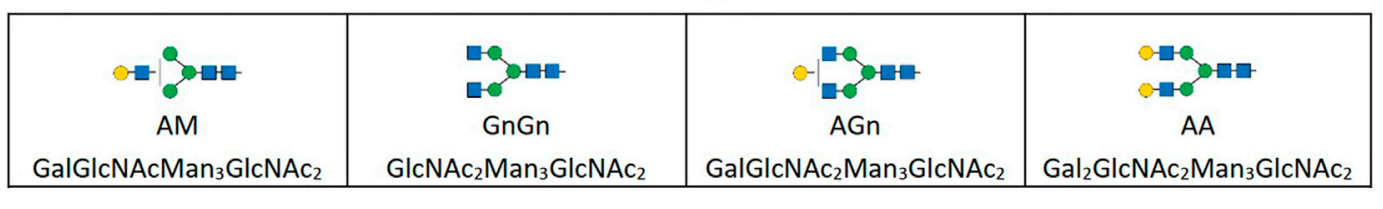

Galactose, A $\square$ GlcNAc, Gn $\bigcirc$ Mannose, $M \quad \star$ Pentose, $P$

FIGURE 1 | MS analysis of X24-derived rhEPO glycopeptide HCSLNENITVPDTK. (A) Precursor mass range (27.6-28.7 min) displaying the X24-derived triple charged $\left(\left[\mathrm{M}+3 \mathrm{H}^{+}\right]^{+}\right)$glycopeptide HCSLNENITVPDTK with different $N$-glycans attached. (B) An average mass shift of 14.0157 Da between the calculated single charged $\left(\left[\mathrm{M}+1 \mathrm{H}^{+}\right]^{+}\right)$precursor masses (from left to right: $1216.1676\left(\left[\mathrm{M}+3 \mathrm{H}^{+}\right]^{+}\right) \rightarrow 3646.4882\left(\left[\mathrm{M}+1 \mathrm{H}^{+}\right]^{+}\right) ; 1220.8393\left(\left[\mathrm{M}+3 \mathrm{H}^{+}\right]^{+}\right) \rightarrow 3660.5033\left(\left[\mathrm{M}+1 \mathrm{H}^{+}\right]^{+}\right) ; 1225.5116$ $\left.\left(\left[\mathrm{M}+3 \mathrm{H}^{+}\right]^{+}\right) \rightarrow 3674.5202\left(\left[\mathrm{M}+1 \mathrm{H}^{+}\right]^{+}\right) ; 1230.1816\left(\left[\mathrm{M}+3 \mathrm{H}^{+}\right]^{+}\right) \rightarrow 3688.5302\left(\left[\mathrm{M}+1 \mathrm{H}^{+}\right]^{+}\right)\right)$indicates the addition of methyl groups. Me: methyl, monoisotopic mass shift: +14.0157 Da. (C) Abbreviations and corresponding cartoons for non-pentosylated glycan structures described in this work. $N$-glycans are depicted according to the glycan nomenclature of the Consortium for Functional Glycomics (http://www.functionalglycomics.org), while the attachment of an unknown pentose is depicted as a red star.

reviewed (Jefferis, 2009; Li and d'Anjou, 2009; Tan et al., 2018). Terminal $\mathrm{N}$-glycan sialylation increases the protein surface charge and hides the underlying sugars galactose, GlcNAc and mannose. Renal filtration and elimination rates are retarded for highly charged proteins (Solá and Griebenow, 2010). Additionally, liver asialoglycoprotein receptors recognizing terminal galactose, as well as mannose receptors, mainly on immune cells, recognizing terminal mannose or GlcNAc, are responsible for a rapid clearance of non-sialylated glycoproteins from serum (Datta-Mannan, 2019).

To reach $N$-glycan sialylation, which has already been stably attained in N. benthamiana and Physcomitrella (Kallolimath et al., 2016; Bohlender et al., 2020), the galactosylated $N$-glycan acceptor should be provided as a first step. In planta $N$-glycan $\beta 1,4-$ galactosylation has been achieved via expression of heterologous coding sequences (CDSs) of different versions of $\beta 1,4$ galactosyltransferases $(\beta 1,4-\mathrm{GalT})$, including the sequences of various animal species along with the human one and chimeric varieties thereof (Palacpac et al., 1999; Bakker et al., 2001, 2006; Misaki et al., 2003; Huether et al., 2005; Fujiyama et al., 2007; Hesselink et al., 2014; Kittur et al., 2020; Kriechbaum et al., 2020). In these various approaches in different plant species, it has become evident that galactosylation efficiency and quality is influenced by diverse factors. Among them, localization of the enzyme within the Golgi apparatus plays an important role. When localized too early in the Golgi sub-compartments, the $\beta 1,4$-GalT activity interferes with the activities of the $\alpha$-mannosidase II (GMII) or the $\mathrm{N}$-acetylglucosaminyltransferase II (GnTII), impeding further $\mathrm{N}$-glycan maturation and leading to incompletely processed mono-antennary galactosylated $\mathrm{N}$-glycans (Strasser et al., 2009; Schneider et al., 2015; Kallolimath et al., 2018). The localization of a protein anchored in the endomembrane system is dependent on the N-terminal cytoplasmic, transmembrane and stem (CTS) domain (Czlapinski and Bertozzi, 2006; Schoberer and Strasser, 2011; Welch and Munro, 2019). Accordingly, the CTS of the human $\beta 1,4-G a l T$, which is apparently localized in the early to 
medial plant Golgi apparatus was replaced by CTS sequences with an assumed late trans-Golgi localization. Chimeric variants of the $\beta 1,4-$ GalT with different CTS domains, like the CTS of the human sialyltransferase (Strasser et al., 2009), the CTS of the Arabidopsis $\beta 1,3$-galactosyltransferase 1 (Kriechbaum et al., 2020) or the CTS of the Physcomitrella $\alpha 1,4$-fucosyltransferase (FTGT) (Bohlender et al., 2020) have been described and led to higher shares of di-antennary galactosylated $\mathrm{N}$-glycans. Furthermore, the target glycoprotein itself influences its galactosylation efficiency (Kriechbaum et al., 2020), probably based on conformation-related accessibility.

In this study we analyzed the galactosylation efficiency of the chimeric $\beta 1,4$-galactosyltransferase FTGT, which consists of the CTS domain of the moss $\alpha 1,4$-fucosyltransferase fused to the catalytic domain of the human $\beta 1,4-G a l T$ (Bohlender et al., 2020). Differing from the protein employed in our previous study, here we use recombinant human erythropoietin (rhEPO). Human EPO is a highly glycosylated protein hormone which inhibits apoptosis of erythroid progenitor cells and stimulates their differentiation, increasing the number of circulating mature red blood cells (Jelkmann, 2013). Recombinant hEPO is widely used for the treatment of severe chronic anemia especially associated with chronic kidney disease and chemotherapy (Jelkmann, 2013). Additionally, non-sialylated rhEPO (asialorhEPO) is of pharmacological interest due to its tissue-protective activity devoid of erythropoietic activity (Peng et al., 2020).

FTGT expression led to a galactosylation efficiency of about $66 \%$ on rhEPO $\mathrm{N}$-glycans, and $65 \%$ of the galactosylated fraction consisted of mature di-antennary galactosylated structures. However, up to five additional pentoses were found to be attached to about $92 \%$ of all $\beta 1,4$-galactosylated $N$-glycans. Pentosylation on $\beta 1,4$-galactosylated $N$-glycans was recently reported in N. tabacum and Physcomitrella (Bohlender et al., 2020; Kittur et al., 2020), indicating that this modification might affect different plant-based production systems; but so far no reports are available elucidating its identity. Here, we identified the unknown pentoses as $\alpha$-linked arabinofuranoses. The arabinose identity was verified by immunoblot-based detection on rhEPO with an antia1,5-arabinan antibody and specific digestion of the pentoses from rhEPO with $\alpha$-L-arabinofuranosidase, confirmed via immunoblot and mass spectrometry analysis.

Arabinoses are not present in humans, and therefore potentially immunogenic (Anderson et al., 1984; Steffan et al., 1995; Leonard et al., 2005). Moreover, they might interfere with the efficient establishment of in planta sialylation. In this regard, the characterization of the undesired pentosylation as $\alpha-\mathrm{L}$ arabinosylation is an indispensable step towards the identification of the responsible glycosyltransferase and thus to provide plant-based glyco-engineered biopharmaceuticals with tailored $N$-glycosylation patterns.

\section{MATERIALS AND METHODS \\ Plant Material and Generation of Transgenic Moss Lines}

Physcomitrella (Physcomitrium patens) was cultivated as described previously (Frank et al., 2005). The recombinant human EPO (rhEPO)-producing moss line 174.16 (Weise et al., 2007; Parsons et al., 2013) is based on the Physcomitrella $\Delta \mathrm{xt} / \Delta \mathrm{ft}$ double knockout line lacking $\beta 1,2-$ xylosyltransferase and $\alpha 1,3$-fucosyltransferase activity (Koprivova et al., 2004, IMSC no.: 40828). This line produces and secretes rhEPO with a predominant GnGn-glycosylation pattern, partially decorated with additional $\mathrm{Le}^{\mathrm{a}}$ epitopes $(\beta 1,3-$ galactosylation and a1,3-fucosylation) to the culture medium. The moss line $\Delta$ galt1 was obtained previously by targeted knockout of the moss-endogenous $\beta 1,3$-galactosyltransferase 1 (GalT1, Pp3c22_470V3.1) in line 174.16 (Parsons et al., 2012). This line produces rhEPO devoid of any plant-specific sugar residues. Human-like $\beta 1$,4-galactosylation was established based on the line 174.16 via the homologous integration of a chimeric $\beta 1,4-G a l T$-containing expression cassette (Bohlender et al., 2020) into the GalT1-encoding locus to achieve simultaneous GalT1 depletion. This chimeric variant, FTGT, contains the CTS domain of the moss-endogenous a1,4-fucosyltransferase (Pp3c18_90V3.1) fused to the catalytic domain of the human $\beta 1,4-G a l T$ (NM_001497.4) and is driven by the long 35S promoter (Horstmann et al., 2004). Resistance to Zeocin was used to select transformed plants (Bohlender et al., 2020).

\section{Protein Precipitation from Culture Supernatant}

For rhEPO production, the respective Physcomitrella lines were inoculated at an initial density of $0.6 \mathrm{~g}$ dry weight (DW)/L and cultivated for 10 days (Parsons et al., 2012). Recombinant hEPO was recovered from culture supernatant by precipitation with trichlorocetic acid as described before (Büttner-Mainik et al., 2011).

\section{Enzymatic Arabinose Digestion}

Protein pellets recovered from culture supernatant and containing moss-produced rhEPO were dissolved in a $100 \mathrm{mM}$ sodium acetate buffer containing 2\% SDS ( $\mathrm{pH} 4.0$ ). After $10 \mathrm{~min}$ shaking (1,200 rpm, Thermomix, Eppendorf) at $90^{\circ} \mathrm{C}$ and additional $10 \mathrm{~min}$ centrifugation at $15,000 \mathrm{rpm}$ the supernatant was transferred to a fresh $1.5 \mathrm{ml}$ reaction tube. SDS was removed from the samples using Pierce ${ }^{\mathrm{TM}}$ detergent removal spin columns $(0.5 \mathrm{ml}$, Thermo Fisher Scientific) according to the manufacturer's instructions. Total protein concentration was determined using bicinchoninic acid assay (BCA Protein Assay Kit; Thermo Fisher Scientific) following the manufacturer's instructions. For each analyzed line, $10 \mu \mathrm{g}$ of total protein were mixed with one unit of $\alpha$-L-arabinofuranosidase from either Aspergillus niger or a corresponding recombinant version (E-AFASE or E-ABFCJ, Megazyme, Bray, Ireland) and incubated over night at $40^{\circ} \mathrm{C}$. In parallel, enzyme-free samples from each moss line were treated under the same conditions.

\section{SDS-PAGE and Western Blot}

For SDS-PAGE, samples of 5-10 $\mu$ g protein were reduced with $50 \mathrm{mM}$ dithiothreitol (DTT) for $15 \mathrm{~min}$ at $90^{\circ} \mathrm{C}$ and mixed with $4 \times$ sample loading buffer (Bio-Rad, Munich, Germany). Protein separation was carried out via SDS-PAGE in $12 \%$ polyacrylamide 
gels (Mini-PROTEAN ${ }^{\circledast}$ TGX $^{\mathrm{TM}}$ Precast Gels, Bio-Rad, Munich, Germany) in TGS buffer (Bio-Rad) at $120 \mathrm{~V}$. For molecular weight comparison the PageRuler ${ }^{\mathrm{TM}}$ Prestained Protein Ladder (26616, Thermo Fisher Scientific) was used. After electrophoretic separation, proteins were transferred to a polyvinylidene fluoride (PVDF) membrane (Cytiva) using a Trans-Blot SD Semi-Dry Electrophoretic Cell (Bio-Rad) with $1.5 \mathrm{~mA} / \mathrm{cm}^{2}$ membrane for $1 \mathrm{~h}$. After blotting, the membrane was blocked in $0.1 \%$ Tween 20 in TBS (TBST) with $4 \%$ ECL blocking agent (Cytiva) at $4^{\circ} \mathrm{C}$ over night. For arabinose Western blots, the membrane was incubated for 1 hour at room temperature with LM6-M anti-1,5- $\alpha-\mathrm{L}-$ arabinan antibody (Plant Probes, Leeds, United Kingdom) diluted 1:10 in TBST with 2\% ECL blocking agent (Cytiva). After three times washing with TBST for $15 \mathrm{~min}$, the blot was incubated with a peroxidase-linked rabbit anti-rat secondary antibody (Ab6250, Abcam, Cambridge, United Kingdom) diluted 1:25,000 in TBST with $2 \%$ ECL blocking agent. Detection was performed by chemiluminescence development (ECL $^{\mathrm{TM}}$ Advance Western Blotting Detection Kit, Cytiva) according to the manufacturer's instructions. For rhEPO Western blot the membrane was stripped after the arabinose Western blot. For this, the membrane was incubated two times for $10 \mathrm{~min}$ in mild stripping buffer (1.5\% glycine (w/w), $0.1 \%$ SDS (w/w), 1\% Tween 20 (v/v), pH 2.2) and afterwards washed three times for $10 \mathrm{~min}$ with TBST under gentle shaking. After overnight membrane blocking (4\% ECL blocking agent in TBST), anti-hEPO monoclonal antibody (MAB2871; R\&D Systems, Minneapolis, $\mathrm{MN}$, United States) and peroxidase-linked anti-mouse secondary antibody (NA 9310V, Cytiva) in 1:4,000 and 1: 100,000 dilutions, respectively, were used.

\section{Mass Spectrometry}

The $N$-glycosylation pattern on rhEPO was analyzed via mass spectrometry (MS) on glycopeptides obtained by double digestion with trypsin and GluC. For this, the samples were reduced as described above and additionally S-alkylated with a final concentration of $120 \mathrm{mM}$ iodoacetamide (IAA) for $20 \mathrm{~min}$ at RT in darkness prior to SDS-PAGE. After Coomassie staining as described previously (Bohlender et al., 2020), bands corresponding to the molecular weight of rhEPO, ranging between 20 and $40 \mathrm{kDa}$, were cut. Double digestions were performed with trypsin (Promega, Walldorf, Germany) and GluC (Thermo Fisher Scientific) in $100 \mathrm{mM}$ ammonium bicarbonate solution at $37^{\circ} \mathrm{C}$ overnight. Peptide recovery and sample cleanup were performed as described in Top et al. (2019). The initial MS analysis comparing the three test lines (I10, X13 and X24) was performed on a Q-TOF istrument as described in Michelfelder et al. (2017). Glycopeptides were identified from processed Mascot mgf files using custom Perl scripts. A precursor mass tolerance of $15 \mathrm{ppm}$ was used to search for glycopeptide precursors. Glycopeptide identity was confirmed by the presence of typical $\mathrm{N}$-glycan fragments such as GlcNAc oxonium ions (m/ z-values: $[\mathrm{GlcNAc}]^{+}=204.087,\left[\mathrm{GlcNAc}-\mathrm{H}_{2} \mathrm{O}\right]^{+}=186.076$, $\left[\mathrm{GlcNAc}-2 \mathrm{H}_{2} \mathrm{O}\right]^{+}=168.066$, [GlcNAc $\left.-\mathrm{C}_{2} \mathrm{H}_{4} \mathrm{O}_{2}\right]^{+}=144.065$, $\left[\mathrm{GlcNAc}-\mathrm{CH}_{6} \mathrm{O}_{3}\right]^{+}=138.055$, [GlcNAc $\left.\left.-\mathrm{C}_{2} \mathrm{H}_{6} \mathrm{O}_{3}\right]^{+}=126.055\right)$ and glycan fragment ions ([GlcNAcHex $]^{+}=366.139$, $\left[\text { GlcNAcHex }_{2}\right]^{+}=$528.191, [GlcNAcHexPent $]^{+}=498.1818$, $\left[\text { GlcNAcHexPent }_{2}\right]^{+}=630.2241, \quad\left[\text { GlcNAcHexPent }_{3}\right]^{+}=$ 762.266, [GlcNAcHexPent $]^{+}=894.3087$ ) at a fragment mass tolerance of $0.05 \mathrm{Da}$. Spectra were plotted from mgf files and labeled using custom Perl scripts an R (www.R-project.org). Lists of all searched precursor masses and identified glycopeptides are available in Supplementary Tables S1, S2, respectively.

Further MS analyses were performed on a QExative Plus instrument (Thermo Scientific ${ }^{\mathrm{TM}}$, Bremen, Germany) as described previously (Top et al., 2019). Identification of glycopeptides and quantitation was performed as described in Bohlender et al. (2020). In brief, glycopeptides were identified with custom Perl scripts from Mascot mgf files of processed raw data. Precursors were matched at a mass tolerance of $5 \mathrm{ppm}$ and resulting spectra were scanned for the presence of typical glycosylation reporter ions such as GlcNAc oxonium ions (m/ Z-values: $[\mathrm{GlcNAc}]^{+}=204.087,[\mathrm{GlcNAc}-\mathrm{H} 2 \mathrm{O}]^{+}=186.076$, $\left[\text { GlcNAc }-2 \mathrm{H}_{2} \mathrm{O}\right]^{+}=168.066$, [GlcNAc $\left.-\mathrm{C}_{2} \mathrm{H}_{4} \mathrm{O}_{2}\right]^{+}=144.065$, $\left[\mathrm{GlcNAc}-\mathrm{CH}_{6} \mathrm{O}_{3}\right]^{+}=138.055$, $\left.\left[\mathrm{GlcNAc}-\mathrm{C}_{2} \mathrm{H}_{6} \mathrm{O}_{3}\right]^{+}=126.055\right)$ and glycan fragment ions $\left([\mathrm{GlcNAcHex}]^{+}=366.139\right.$, $\left.[\mathrm{GlcNAcHex}]^{+}=528.191\right)$. For fragment ion matching a mass tolerance of $0.02 \mathrm{Da}$ was specified. Quantitative values (peak areas) for the identified glycopeptides were extracted using a custom Perl script from the all Peptides.txt file obtained from a default MaxQuant (V1.6.0.16, Cox and Mann (2008)) search on the respective raw data. A list of searched glycopeptides and their calculated precursor masses as well as a list of identified glycopeptides is available from Supplementary Tables S3, S4. Quantitative values were normalized against the total intensity (sum of all peak areas) of the measurement and added together for precursors identified in different charge stages (Supplementary Tables S5, S6).

All mass-spectrometry data have been deposited to the ProteomeXchange Consortium via the PRIDE partner repository (Perez-Riverol et al., 2019) with the dataset identifier PXD030443.

\section{Statistics}

Mass spectrometry data were obtained from technical triplicates. For statistical analyses one-way ANOVA with Šidák's multiple comparison test was performed. Compared were the means of corresponding galactosylated structures of the different treatments. The $a$-level was set to 0.05 .

\section{RESULTS}

\section{Expression of FTGT Leads to Efficient $\mathbf{N}$ - Glycan $\beta 1,4$ Galactosylation on rhEPO and Attachments of Additional Unknown Pentoses}

To achieve mature $\beta 1,4$-galactosylation on rhEPO in moss, the plant 174.16, which produces rhEPO devoid of plant-specific xylose and a1,3-attached core fucose (Weise et al., 2007) was transformed with the expression construct coding for the chimeric $\beta 1,4$-galactosyltransferase FTGT (Bohlender et al., 2020). This construct is targeted to the genomic locus encoding the $\beta 1,3$-galactosyltransferase 1 , galt1. Gene knockout via targeted integration in the galt1 locus was confirmed by PCR, therefore 
presence of galactose on rhEPO glycopeptides can be inferred to be $\beta 1,4$-linked and not $\beta 1,3$ (Parsons et al., 2012). Three lines (I10, $\mathrm{X} 13$ and X24) were chosen for MS-based rhEPO glycopeptide analysis. A first MS survey revealed galactosylation in all three lines and on all three rhEPO $N$-glycosylation sites. However, in line I10 almost no di-antennary galactosylated structures were detected, and in line X13 a larger proportion of immature $N$-glycans, such as AM structures and a broader heterogeneity of $N$-glycans at the three different glycosylations sites, compared to line X24, were observed (Supplementary Table S2). Therefore, line X24 was chosen for further studies.

In addition to the expected galactosylation, single or multiple mass additions of $132.0423 \mathrm{Da}$, unknown from the $N$-glycans before the introduction of FTGT, were observed. These mass additions, which correspond to the monoisotopic mass of one or multiple attached pentose residues, were detected in all three analyzed FTGTexpressing lines (Supplementary Table S2). Characteristic reporter ions of $\mathrm{N}$-glycan fragments bound to pentoses were detected on $\mathrm{MS}^{2}$ spectra for all rhEPO glycopeptides (Supplementary Figure S1). This indicates an attachment of the pentoses to the $\mathrm{N}$-glycans and not directly to the peptide backbone.

While up to three pentoses were detected on mono-antennary galactosylated $\mathrm{N}$-glycans, mass shifts corresponding to up to five pentoses were measured on di-antennary galactosylated $N$-glycans (exemplarily depicted in Figure 1A for the rhEPO glycopeptide HCSLNENITVPDTK). Additionally, some pentosylated $N$-glycan structures carried single or multiple mass increments of $14.0157 \mathrm{Da}$, characteristic for methyl groups. These mass increments occurred as one or up to the number of attached pentoses (Figure 1, Supplementary Figure S2). From this analysis it was not immediately obvious if the detected structures were methylpentoses or deoxy-hexoses (e.g., fucoses), as the monoisotopic mass of a deoxy-hexose matches that of a methyl-pentose.

\section{Western Blot of rhEPO with an Arabinose-specific Antibody}

As a first step to identify the nature of the unknown pentoses attached to $\mathrm{N}$-glycans, proteins recovered from the culture supernatants of the $\beta 1,4$-galactosylating moss line X24, the parental line 174.16, and line $\Delta$ galt1 (devoid of any $N$-glycan galactosylation), were analyzed via Western blot with the antibody LM6-M, which recognizes short a-L-1,5-arabinan chains (Cornuault et al., 2017). For each line a strong and defined signal at a high molecular weight range $(>180 \mathrm{kDa})$ was observed, which in Physcomitrella is known to be associated with arabinogalactan-proteins (Lee et al., 2005). In the lower molecular weight range, a signal of around $37 \mathrm{kDa}$ was detected exclusively in the X24 sample (Figure 2A). To check if this signal is related to rhEPO, a subsequent anti-hEPO detection was performed (after antibody stripping from the membrane). This anti-hEPO immunodetection revealed rhEPO-corresponding signals between 27 and $37 \mathrm{kDa}$ in all analyzed lines (Figure 2B). The signal with the lowest molecular weight was detected in $\Delta$ galt1, which displays the most reduced glycosylation pattern of the three investigated lines. The intermediate signal was derived from the line 174.16, while the signal with the highest molecular weight,

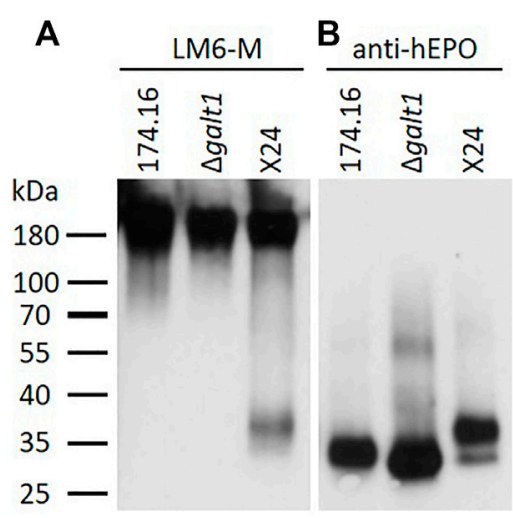

FIGURE 2 | Western blots of precipitated culture supernatants of rhEPO-producing Physcomitrella lines. Five microgram total protein of the precipitated and blotted culture supernatants of the rhEPO-producing lines 174.16, $\Delta$ galt1 and X24 were subsequently immunodetected with the anti-1,5- $\alpha$-L-arabinan antibody (LM6-M, 1:10) (A) and the anti-hEPO monoclonal antibody $(1: 4,000) \mathbf{( B )}$.

ranging from 30 to $37 \mathrm{kDa}$, was detected in $\mathrm{X} 24$, which fits to an increased molecular weight of the rhEPO-attached $N$-glycans due to additional galactosylation and pentosylation. This upper part of the rhEPO-corresponding band detected in line X24 overlaps with the position of the signal detected with the LM6-M antibody (Figure 2A). Therefore, we conclude that the LM6-M antibody detects arabinoses on rhEPO produced in moss line X24.

\section{Specific Enzymatic Activity of $\alpha$-L-Arabinofuranosidase on X24-produced rhEPO Confirmed Arabinosylation}

To further investigate the detected arabinose residues attached to $\beta 1,4$-galactosylated rhEPO $N$-glycans, samples of all three rhEPOproducing lines were digested with $\alpha$-L-arabinofuranosidase. The enzyme-treated samples were first analyzed via immunodetection with LM6-M antibodies followed by a detection with anti-hEPO antibodies and compared to mock-treated samples, as a control for possible non-enzymatic hydrolysis.

With the $a$-L-arabinan-detecting LM6-M antibody, samples treated without $\alpha$-L-arabinofuranosidase show a similar band profile to the untreated samples analyzed previously. Only in the sample from moss line X24 could a band in the lower molecular weight range of about $37 \mathrm{kDa}$ be detected. Strong LM6-M-derived signals for all undigested samples were observed above $180 \mathrm{kDa}$, corresponding to arabinogalactan-proteins (Figures 2A, 3A). These high-molecular weight signals disappeared from the $\alpha$ L-arabinofuranosidase-digested samples, supporting the activity of the enzyme, which is able to digest the 1,5-linked arabinans known to be attached to arabinogalactan-proteins in Physcomitrella (Lee et al., 2005). Furthermore, the arabinosespecific LM6-M-derived signal also disappeared from the digested X24 sample (Figure 3A). The rhEPO-corresponding signals, however, were detected in all samples with the hEPOspecific antibody Western blot (Figure 3B), supporting the 


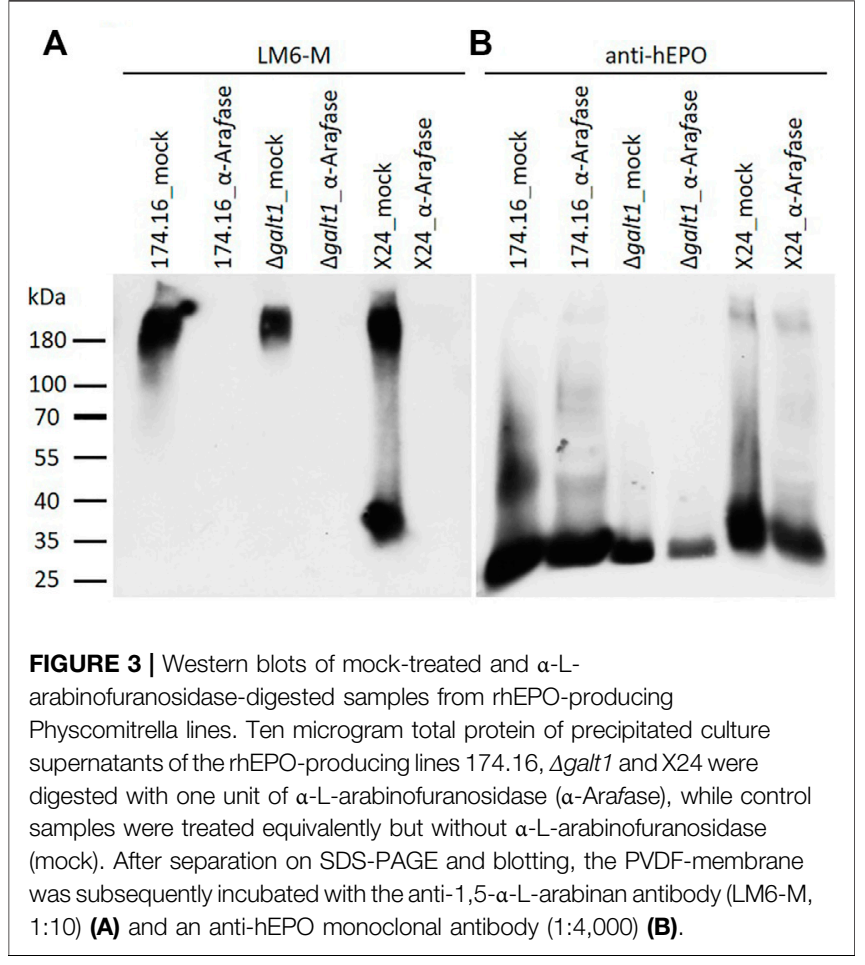

hypothesis that the absence of an arabinose-specific signal after $\alpha$ L-arabinofuranosidase digest is due to the loss of $\mathrm{N}$-glycanattached arabinoses on rhEPO in the $\beta 1$,4-galactosylating line X24.

\section{Mass-spectrometric Validation of Enzymatic Digestion of Arabinoses on rhEPO Produced in the $\beta 1,4-G a l a c t o s y l a t i n g$ Moss Line}

The exact effect of the $\alpha$-L-arabinofuranosidase treatment on rhEPO-glycopeptides of the $\beta 1,4$-galactosylating line X24 was further analyzed in triplicates via mass spectrometry in comparison to undigested samples. The total $N$-glycan distribution in rhEPO was estimated by adding together quantitative values (peak areas) from detected glycopeptides. Values were further added together for $\mathrm{N}$-glycan classes across all three rhEPO $\mathrm{N}$-glycosylation sites (Figure 4). For easier comparison, the quantitative values of all pentose-carrying $\mathrm{N}$ glycan structures were also added together, in order to distinguish the total pentosylated and non-pentosylated proportion of an identified structure (Figure 4A). A detailed breakdown of all identified structures and modifications is given in the Supplementary Table S4 and the quantification is depicted in the Supplementary Figure S2. The MS data of X24-derived rhEPO glycopeptides from $\alpha$-L-arabinofuranosidase-digested and undigested samples showed a total amount of galactosylated $\mathrm{N}$-glycans (comprising pentosylated and nonpentosylated $\mathrm{AM}, \mathrm{AGn}$, and $\mathrm{AA}$ structures, abbreviations explained in Figure 1C) of about $66 \%$ each. Also the

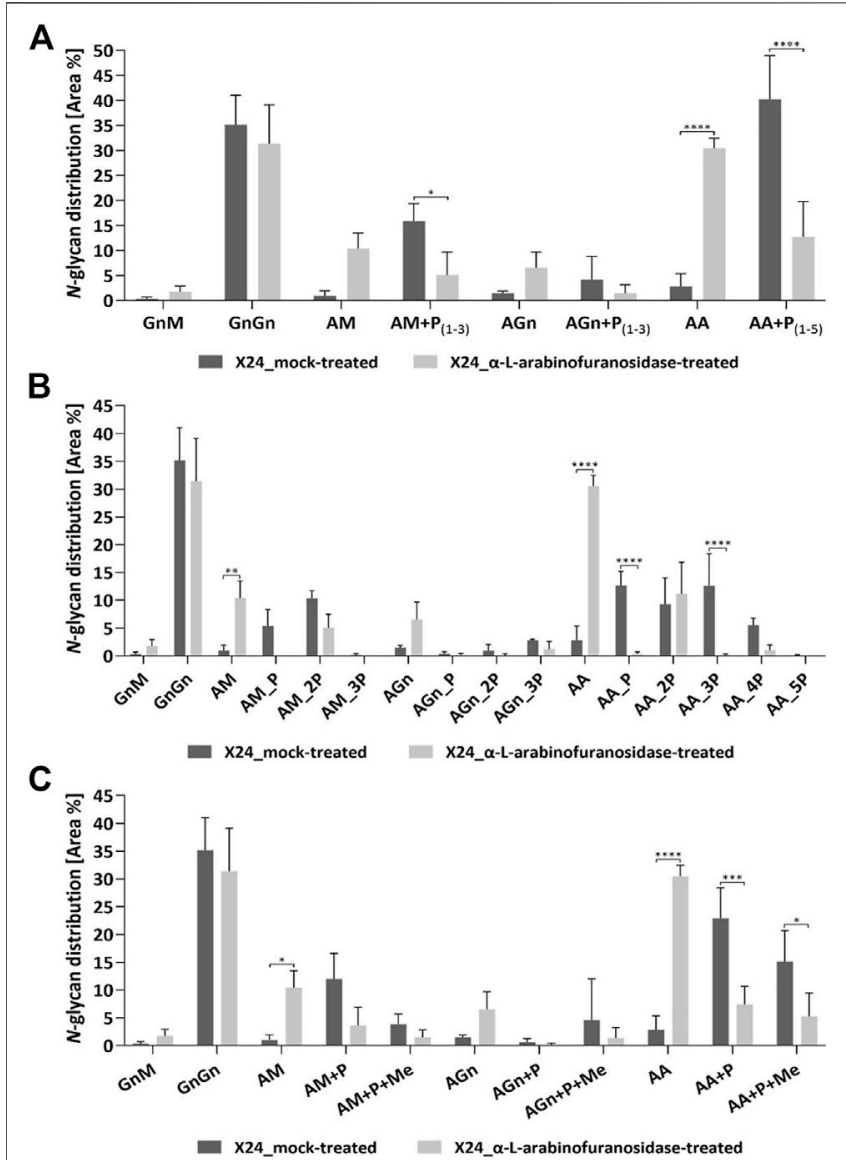

FIGURE 4 | Quantitative MS/MS analysis of the $N$-glycan distribution on rhEPO from $\alpha$ - L-arabinofuranosidase treated in comparison to mock-treated samples. Prior to MS analysis X24derived rhEPO containing samples were digested with $\alpha-L$ arabinofuranosidases, and mock-treated samples without enzyme addition were prepared in parallel. Quantitative values are derived from detected glycopeptides. For a better visualization of the results, the nomenclature for isomeric structures was simplified (e.g., AM, MA or a mixture of both are all displayed as AM). (A) N-glycosylation patterns of rhEPO are represented as relative percentages of all identified $\mathrm{N}$-glycan structures within a category ( $\alpha$-L-arabinofuranosidasetreated or mock-treated). For easier comparison, the quantitative values of all pentose-carrying $N$-glycan structures were further added together, thus from each structure the total non-pentosylated and, if applicable, pentosylated shares are depicted. The presence of pentoses on $\mathrm{N}$-glycan structures is displayed as $+\mathrm{P}$, while the range of detected pentoses on the corresponding structure is given in subscripted numbers. (B) For a more detailed representation of the data, the pentosylated share of each $N$-glycan structure was further depicted according to the defined number of pentoses (indicated as $\mathrm{nP}$ ) identified on the respective structure. A quantitative profile depicting the share of methylation $(+\mathrm{Me})$ on the identified $\mathrm{N}$-glycan structures is given in (C). Depicted is the mean of three technical replicates with standard deviation. Stars indicate significance levels from a one-way ANOVA ( $\alpha=0.05)$ with subsequent Šidák's post hoc test $\left({ }^{\star}: p<0.05 ;{ }^{\star \star}: p<0.01 ;{ }^{\star \star \star}: p<0.001 ;{ }^{\star \star \star \star}: p<0.0001\right) . \mathrm{M}$ : mannose, Gn: N-acetylglucosamine, A: galactose, P: pentose. A detailed breakdown of all identified structures and modifications is given in the Supplementary Table $\mathbf{S} \mathbf{4}$ and the quantification is depicted in the Supplementary Figure S2. 
proportion of mono- (AM, AGn) and di-antennary (AA) processed structures within the galactosylated fraction was the same in both conditions, approximately 35 and $65 \%$, respectively. However, in the undigested samples $92 \%$ of the galactosylated $\mathrm{N}$ glycans were found to be pentosylated, while in the $a-\mathrm{L}$ arabinofuranosidase-treated samples only $29 \%$ of the galactosylated structures remained pentosylated (Figure 4A). The number of pentoses on galactosylated $\mathrm{N}$-glycans in the undigested approach were $28 \%$ single, $31 \%$ double, $24 \%$ triple, $8.5 \%$ quadruple and less than $1 \%$ quintuple attachments. The $\alpha-$ $\mathrm{L}$-arabinofuranosidases cleaved the pentoses from $\mathrm{N}$-glycans, without a clear selectivity for only one pentose or up to five pentoses at once, leading to a high amount of structures with complete pentose removal and a clear increase of the corresponding $\mathrm{N}$-glycan structure with terminal galactose (Figures 4A,B). This suggests that the remaining pentoses on the digested sample are not present due to enzyme specificity but rather to incomplete efficiency of the enzyme. Finally, we analyzed the single and multiple mass increments of $14.0157 \mathrm{Da}$ in digested and non-digested samples. The fraction of pentosylated structures with 14.0157 Da increments remained constant after digestion with a-L-arabinofuranosidases. In both treatments about $40 \%$ of the pentosylated glycans carried this modification, indicating that the a-L-arabinofuranosidases activity decreased the amount of all pentosylated structures, regardless of the presence of the 14.0157 Da mass increments (Figure 4C).

The maximal number of identified 14.0157 Da mass additions on pentosylated $\mathrm{N}$-glycan structures matches the number of attached pentoses and this mass shift was not observed on non-pentosylated $\mathrm{N}$-glycans (Figure 1A). Moreover, these additions did not interfere with the specific arabinose-cleaving activity of the enzymes and disappeared when the pentoses were cleaved from $\mathrm{N}$-glycans (Figure 4C). Therefore, and consistent with the specificity of the enzymes, we conclude that the detected masses attached to the galactosylated $\mathrm{N}$-glycans are a-linked arabinofuranoses, which are occasionally methylated.

\section{DISCUSSION}

Glycosylation, a frequent and complex posttranslational modification of proteins, is a critical quality feature for glycoprotein-based therapeutics, as it influences their conformation, solubility, activity, pharmacokinetics and antigenicity (Arnold et al., 2007; Solá and Griebenow, 2010). The composition of the respective $\mathrm{N}$-glycans is dictated by intrinsic characteristics of the protein itself, such as conformation, as well as by the glycan-processing enzymes of the production platform (Clausen et al., 2015; Suga et al., 2018). N-glycosylation of most biopharmaceutical production hosts, even the predominantly used mammalian cell systems, differ to their human counterparts to different extents (Wang et al., 2015). For instance, $\mathrm{N}$-glycolylneuraminic acid (Neu5Gc), a sialic acid not existing in humans and consequently associated with antibody formation (Tangvoranuntakul et al., 2003; Padler-Karavani et al., 2011), can be found on $\mathrm{N}$-glycans of glycoproteins produced in some nonhuman mammalian cell lines (Varki, 2001; Ghaderi et al., 2012).
Although plant $\mathrm{N}$-glycosylation differs from the human pattern, its humanization, which includes the removal of plant-specific sugar residues, the introduction of a $\beta 1,4$-galactosylation capacity and the final establishment of terminal $N$-glycan sialylation, has been performed to varying degrees in different plant systems (reviewed in Montero-Morales and Steinkellner, 2018). These studies have demonstrated a great flexibility of plants towards glyco-engineering. Especially the moss Physcomitrella offers the additional advantages of a high rate of homologous recombination in mitotic cells, a characteristic feature used for efficient precise genome editing, and a haploid gametophytic tissue, which enables immediate implementation of glyco-modifications (Parsons et al., 2012; Decker et al., 2014; Wiedemann et al., 2018).

The $\beta 1,4$-linked galactoses on $\mathrm{N}$-glycans provide the anchor for sialic acid, but terminal galactose also plays an important role in non-sialylated glycoproteins. For example, asialo-EPO was proposed to be neuroprotective (Erbayraktar et al., 2003; Peng et al., 2020) and on the Fc domains of monoclonal antibodies terminal $\mathrm{N}$-glycan galactosylation increases complementdependent (Hodoniczky et al., 2005) as well as antibodydependent cytotoxicity (Thomann et al., 2016).

In terms of de novo $\beta 1,4$-galactosylation in plants, its efficiency and degree of maturation (mono- or di-antennary) depends on the expression level of the respective galactosyltransferase (Kallolimath et al., 2018), its Golgi localization, determined by the N-terminal CTS domain (Strasser et al., 2009; Hesselink et al., 2014; Kriechbaum et al., 2020), and the reporter glycoprotein itself (Schneider et al., 2015; Kriechbaum et al., 2020).

In this study, we established $\beta 1,4$-galactosylation on rhEPO produced in moss devoid of plant-specific sugar residues. To target the $\beta 1,4-G a l T$ activity to the late Golgi compartments, the catalytic domain of this enzyme was fused to the CTS domain of the moss-endogenous a1,4-fucosyltransferase, whose activity is the last known in plant $\mathrm{N}$-glycan maturation (Fitchette et al., 1999; Parsons et al., 2012).

In our earlier study with sialylating moss lines (Bohlender et al., 2020), FTGT-mediated overall galactosylation was up to $89 \%$. From that fraction up to $34 \%$ comprised di-antennary galactosylated structures. In contrast, in the current study, $66 \%$ of all glycans carried galactoses, and $65 \%$ of these were di-antennary galactosylated, indicating a medial- to trans-Golgi localization of the FTGT enzyme. These values are very promising, considering that previous studies reported lower galactosylation efficiencies with up to 20 and $12 \%$ diantennary galactosylated rhEPO produced in N. tabacum or $N$. benthamiana plants, respectively (Kittur et al., 2013; Kriechbaum et al., 2020). However, the galactosylation efficiency on rhEPO produced in $N$. benthamiana was increased by knocking out the $\beta$-galactosidase NbBGAL1, an enzyme responsible for galactose cleavage (Kriechbaum et al., 2020). A similar strategy might be applied to moss.

Accompanying the established human-like galactosylation, we detected the attachment of pentose residues on $\beta 1,4$ galactosylated $\mathrm{N}$-glycans. Up to three pentoses were attached to mono-antennary and up to five pentose residues to diantennary galactosylated $N$-glycans, which indicates the building of short pentose chains. These were not present in 
the corresponding parental line with an intact $\beta 1,3$ galactosyltransferase (Parsons et al., 2012), indicating that naturally occurring $\beta 1,3$-galactosylated $N$-glycans do not display a substrate for this modification.

In planta $\mathrm{N}$-glycan pentosylation on a recombinant protein upon the establishment of $\beta 1,4$-galactosylation has also been observed in N. tabacum (Kittur et al., 2020), suggesting that this phenomenon is not restricted to Physcomitrella but rather affects plant-based production in general. Pentosylation was also observed in sialylating moss lines (Bohlender et al., 2020). However, in these plants either pentoses or sialic acid could be detected on galactosylated $\mathrm{N}$-glycans, indicating that the pentosylation may interfere with the full $\mathrm{N}$-glycan humanization of plant-derived glycoproteins. This observation confers importance to the elucidation of the respective pentose residues.

Based on immunodetection with LM6-M, a monoclonal antibody recognizing short chains of a1,5-linked arabinan (Cornuault et al., 2017), we could identify the pentoses on moss-produced rhEPO as arabinoses. Specific digestion of these pentoses with $a$-L-arabinofuranosidase, an enzyme specifically cleaving $\alpha 1,2-, \alpha 1,3-$ and $\alpha 1,5$-linked arabinofuranoses from arabinan molecules, was verified via immunodetection and supported by MS analysis of rhEPO glycopetides. These findings confirm the identity of the pentoses as (short chains of a-linked arabinofuranoses. Additionally, we found the arabinoses to be occasionally methylated. Some residual pentoses after $\alpha$-L-arabinofuranosidase digest may be attributed to inefficient hydrolysis of $\alpha$-1,5-linked arabino-oligosaccharides by the enzymes used. The fact that these residual pentoses (structures with up to two pentoses) present in the $a-\mathrm{L}-$ arabinofuranosidase-treated sample were not detected by the LM6-M antibody, can be due to the very low concentration of these residual sugars, and the characteristic of LM6-M antibodies that recognize arabinose $e_{2}$ chains with much less avidity than longer arabinose chains, while no information about its avidity towards single arabinose residues is available (Cornuault et al., 2017).

Recently, the presence of arabinose and methylated arabinose on $\mathrm{N}$-glycans of the microalga Chlorella sorokiniana has been described (Mócsai et al., 2020) and in very rare cases methylation of $\mathrm{N}$-glycans in Physcomitrella wild-type strains was detected (Stenitzer et al., 2022). However, we never observed this sugar and any methylation on $\mathrm{N}$-glycans of glyco-engineered Physcomitrella strains before the establishment of human-like $\beta 1,4$-galactosylation. Evidently, an arabinosyltransferase from a different biosynthetic pathway recognizes the $\beta 1,4$-galactosylated $N$-glycan as substrate. Plants display a wide diversity of cell-wall glycans and $O$-glycosylated hydroxyproline-rich glycoproteins (Seifert et al., 2021). This diversity originates from the combination of different monosaccharides and various linkages, generated by a huge variety of glycosyltransferases from which a considerable amount has not been thoroughly characterized yet (Showalter and Basu, 2016; Amos and Mohnen, 2019). Some enzymes responsible for the attachment of arabinoses to $\beta 1,4$-linked galactoses on $O$-glycosylated arabinogalactan proteins as well as in cell-wall associated structures like rhamnogalaturan I have been described, but many still remain unknown (Léonard et al., 2010; Laursen et al., 2018; Ropartz and Ralet, 2020; Petersen et al., 2021). The identification of the enzyme or enzymes responsible for the arabinosylation of galactosylated $\mathrm{N}$-glycans is therefore not a straightforward task.

For the application of plant-based biopharmaceuticals, this newly appearing $N$-glycan attachment bears the risk of immunogenicity in patients, as arabinose is a sugar not produced in humans (Anderson et al., 1984; Steffan et al., 1995; Leonard et al., 2005). To avoid arabinose attachment, the responsible arabinosyltransferases need to be identified and abolished by gene targeting to create stable lines devoid of $\mathrm{N}$-glycan arabinosylation. To this aim, our study provides the first important step by elucidating the unknown pentose residues, which helps to ensure the production of safe biopharmaceuticals in plant-based systems.

\section{DATA AVAILABILITY STATEMENT}

The datasets presented in this study can be found in online repositories. The names of the repository/repositories and accession number(s) can be found in the article/ Supplementary Material.

\section{AUTHOR CONTRIBUTIONS}

LLB performed most of the experiments, SNWH performed the MS data analysis, NB performed some Western blot experiments, FRJ created the analyzed lines I10, X13 and X24, LLB, JP, RR and ELD designed the study and wrote the manuscript.

\section{FUNDING}

We gratefully acknowledge funding by the Deutsche Forschungsgemeinschaft (DFG, German Research Foundation) under Germany's Excellence Strategy EXC-2189 (CIBSS to RR) and GSC-4 (SGBM to FRJ). We acknowledge support by the Open Access Publication Fund of the University of Freiburg.

\section{ACKNOWLEDGMENTS}

We thank Agnes Novakovic for technical support to this work. We thank Prof. Dr. Bettina Warscheid for the use of the QExactive Plus instrument, Prof. Dr. Jörn Dengjel and Dr. Verónica I. Dumit for the use of the QTOF instrument and Anne Katrin Prowse for proof-reading of the manuscript.

\section{SUPPLEMENTARY MATERIAL}

The Supplementary Material for this article can be found online at: https://www.frontiersin.org/articles/10.3389/fbioe.2022.838365/ full\#supplementary-material 


\section{REFERENCES}

Amos, R. A., and Mohnen, D. (2019). Critical Review of Plant Cell Wall Matrix Polysaccharide Glycosyltransferase Activities Verified by Heterologous Protein Expression. Front. Plant Sci. 10, 915. doi:10.3389/fpls.2019.00915

Anderson, M. A., Sandrin, M. S., and Clarke, A. E. (1984). A High Proportion of Hybridomas Raised to a Plant Extract Secrete Antibody to Arabinose or Galactose. Plant Physiol. 75, 1013-1016. doi:10.1104/pp.75.4.1013

Arnold, J. N., Wormald, M. R., Sim, R. B., Rudd, P. M., and Dwek, R. A. (2007). The Impact of Glycosylation on the Biological Function and Structure of Human Immunoglobulins. Annu. Rev. Immunol. 25, 21-50. doi:10.1146/annurev. immunol.25.022106.141702

Bakker, H., Bardor, M., Molthoff, J. W., Gomord, V., Elbers, I., Stevens, L. H., et al. (2001). Galactose-extended Glycans of Antibodies Produced by Transgenic Plants. Proc. Natl. Acad. Sci. U.S.A. 98, 2899-2904. doi:10. 1073/pnas.031419998

Bakker, H., Rouwendal, G. J. A., Karnoup, A. S., Florack, D. E. A., Stoopen, G. M., Helsper, J. P. F. G., et al. (2006). An Antibody Produced in Tobacco Expressing a Hybrid Beta-1,4-Galactosyltransferase is Essentially Devoid of Plant Carbohydrate Epitopes. Proc. Natl. Acad. Sci. 103, 7577-7582. doi:10.1073/ pnas.0600879103

Bohlender, L. L., Parsons, J., Hoernstein, S. N. W., Rempfer, C., Ruiz-Molina, N., Lorenz, T., et al. (2020). Stable Protein Sialylation in Physcomitrella. Front. Plant Sci. 11, 610032. doi:10.3389/fpls.2020.610032

Büttner-Mainik, A., Parsons, J., Jérôme, H., Hartmann, A., Lamer, S., Schaaf, A., et al. (2011). Production of Biologically Active Recombinant Human Factor $\mathrm{H}$ in Physcomitrella. Plant Biotechnol. J. 9, 373-383. doi:10.1111/j.1467-7652. 2010.00552.x

Buyel, J. F. (2019). Plant Molecular Farming - Integration and Exploitation of Side Streams to Achieve Sustainable Biomanufacturing. Front. Plant Sci. 9, 1893. doi:10.3389/fpls.2018.01893

Clausen, H., Wandall, H. H., Steentoft, C., Stanley, P., and Schnaar, R. L. (2015). "Glycosylation Engineering," in Essentials of Glycobiology. A. Varki, R. D. Cummings, J. D. Esko, P. Stanley, G. W. Hart, M. Aebi, et al. (Cold Spring Harbor (NY): Cold Spring Harbor Laboratory Press).

Cornuault, V., Buffetto, F., Marcus, S. E., Crépeau, M.-J., Guillon, F., Ralet, M.-C., et al. . (2017). LM6-M: A High Avidity Rat Monoclonal Antibody to Pectic $\alpha$ 1,5-L-arabinan, doi:10.1101/161604

Cox, J., and Mann, M. (2008). MaxQuant Enables High Peptide Identification Rates, Individualized p.p.b.-range Mass Accuracies and Proteome-wide Protein Quantification. Nat. Biotechnol. 26, 1367-1372. doi:10.1038/nbt.1511

Cox, K. M., Sterling, J. D., Regan, J. T., Gasdaska, J. R., Frantz, K. K., Peele, C. G., et al. (2006). Glycan Optimization of a Human Monoclonal Antibody in the Aquatic Plant Lemna minor. Nat. Biotechnol. 24, 1591-1597. doi:10.1038/ nbt1260

Czlapinski, J., and Bertozzi, C. (2006). Synthetic Glycobiology: Exploits in the Golgi Compartment. Curr. Opin. Chem. Biol. 10, 645-651. doi:10.1016/j.cbpa.2006. 10.009

Datta-Mannan, A. (2019). Mechanisms Influencing the Pharmacokinetics and Disposition of Monoclonal Antibodies and Peptides. Drug Metab. Dispos. 47, 1100-1110. doi:10.1124/dmd.119.086488

Decker, E. L., Parsons, J., and Reski, R. (2014). Glyco-engineering for Biopharmaceutical Production in Moss Bioreactors. Front. Plant Sci. 5, 346. doi:10.3389/fpls.2014.00346

Decker, E. L., and Reski, R. (2020). Mosses in Biotechnology. Curr. Opin. Biotechnol. 61, 21-27. doi:10.1016/j.copbio.2019.09.021

Erbayraktar, S., Grasso, G., Sfacteria, A., Xie, Q.-w., Coleman, T., Kreilgaard, M., et al. (2003). Asialoerythropoietin is a Nonerythropoietic Cytokine with Broad Neuroprotective Activity In Vivo. Proc. Natl. Acad. Sci. 100, 6741-6746. doi:10. 1073/pnas.1031753100

Facts and Figures (2021). The Pharmaceutical Industry and Global Health IFPMA. Available at: https://www.ifpma.org/resource-centre/facts-and-figures-2021the-pharmaceutical-industry-and-global-health/ (Accessed December 6, 2021).

Fitchette, A.-C., Cabanes-Macheteau, M., Marvin, L., Martin, B., SatiatJeunemaitre, B., Gomord, V., et al. (1999). Biosynthesis and Immunolocalization of Lewis A-containing $\mathrm{N}$-Glycans in the Plant Cell. Plant Phys. 121, 333-344. doi:10.1104/pp.121.2.333
Frank, W., Decker, E. L., and Reski, R. (2005). Molecular Tools to Study Physcomitrella patens. Plant Biol. 7, 220-227. doi:10.1055/s-2005-865645

Fujiyama, K., Furukawa, A., Katsura, A., Misaki, R., Omasa, T., and Seki, T. (2007). Production of Mouse Monoclonal Antibody with Galactose-extended Sugar Chain by Suspension Cultured Tobacco BY2 Cells Expressing Human $\beta(1,4)$ galactosyltransferase. Biochem. Biophysical Res. Commun. 358, 85-91. doi:10. 1016/j.bbrc.2007.04.054

Ghaderi, D., Zhang, M., Hurtado-Ziola, N., and Varki, A. (2012). Production Platforms for Biotherapeutic Glycoproteins. Occurrence, Impact, and Challenges of Non-human Sialylation. Biotechnol. Genet. Eng. Rev. 28, 147-176. doi:10.5661/bger-28-147

Gomord, V., Fitchette, A.-C., Menu-Bouaouiche, L., Saint-Jore-Dupas, C., Plasson, C., Michaud, D., et al. (2010). Plant-specific Glycosylation Patterns in the Context of Therapeutic Protein Production. Plant Biotechnol. J. 8, 564-587. doi:10.1111/j.1467-7652.2009.00497.x

Grabowski, G. A., Golembo, M., and Shaaltiel, Y. (2014). Taliglucerase Alfa: An Enzyme Replacement Therapy Using Plant Cell Expression Technology. Mol. Genet. Metab. 112, 1-8. doi:10.1016/j.ymgme.2014.02.011

Hanania, U., Ariel, T., Tekoah, Y., Fux, L., Sheva, M., Gubbay, Y., et al. (2017). Establishment of a Tobacco BY2 Cell Line Devoid of Plant-specific Xylose and Fucose as a Platform for the Production of Biotherapeutic Proteins. Plant Biotechnol. J. 15, 1120-1129. doi:10.1111/pbi.12702

Hennermann, J. B., Arash-Kaps, L., Fekete, G., Schaaf, A., Busch, A., and Frischmuth, T. (2019). Pharmacokinetics, Pharmacodynamics, and Safety of Moss-aGalactosidase A in Patients with Fabry Disease. J. Inherit. Metab. Dis. 42, 527-533. doi:10.1002/jimd.12052

Hesselink, T., Rouwendal, G. J. A., Henquet, M. G. L., Florack, D. E. A., Helsper, J. P. F. G., and Bosch, D. (2014). Expression of Natural Human $\beta 1,4-G a l T 1$ Variants and of Non-mammalian Homologues in Plants Leads to Differences in Galactosylation of N-Glycans. Transgenic Res. 23, 717-728. doi:10.1007/ s11248-014-9806-z

Hodoniczky, J., Zheng, Y. Z., and James, D. C. (2005). Control of Recombinant Monoclonal Antibody Effector Functions by Fc N-Glycan Remodeling In Vitro. Biotechnol. Prog. 21, 1644-1652. doi:10.1021/bp050228w

Horstmann, V., Huether, C. M., Jost, W., Reski, R., and Decker, E. L. (2004). Quantitative Promoter Analysis in Physcomitrella patens: A Set of Plant Vectors Activating Gene Expression within Three Orders of Magnitude. BMC Biotechnol. 4, 13. doi:10.1186/1472-6750-4-13

Huether, C. M., Lienhart, O., Baur, A., Stemmer, C., Gorr, G., Reski, R., et al. (2005). Glyco-engineering of Moss Lacking Plant-specific Sugar Residues. Plant Biol. 7, 292-299. doi:10.1055/s-2005-837653

Jansing, J., Sack, M., Augustine, S. M., Fischer, R., and Bortesi, L. (2018). CRISPR/ Cas9-mediated Knockout of Six Glycosyltransferase Genes in Nicotiana Benthamiana for the Production of Recombinant Proteins Lacking $\beta-1,2$ xylose and Core $\alpha-1,3$-fucose. Plant Biotechnol. J. 17, 350-361. doi:10.1111/ pbi.12981

Jefferis, R. (2009). Glycosylation as a Strategy to Improve Antibody-based Therapeutics. Nat. Rev. Drug Discov. 8, 226-234. doi:10.1038/nrd2804

Jelkmann, W. (2013). Physiology and Pharmacology of Erythropoietin. Transfus. Med. Hemother. 40, 302-309. doi:10.1159/000356193

Kallolimath, S., Castilho, A., Strasser, R., Grünwald-Gruber, C., Altmann, F., Strubl, S., et al. (2016). Engineering of Complex Protein Sialylation in Plants. Proc. Natl. Acad. Sci. U.S.A. 113, 9498-9503. doi:10.1073/pnas.1604371113

Kallolimath, S., Gruber, C., Steinkellner, H., and Castilho, A. (2018). Promoter Choice Impacts the Efficiency of Plant Glyco-engineering. Biotechnol. J. 13, 1700380. doi:10.1002/biot.201700380

Kittur, F. S., Bah, M., Archer-Hartmann, S., Hung, C.-Y., Azadi, P., Ishihara, M., et al. (2013). Cytoprotective Effect of Recombinant Human Erythropoietin Produced in Transgenic Tobacco Plants. PLOS ONE 8, e76468. doi:10.1371/ journal.pone.0076468

Kittur, F. S., Hung, C.-Y., Zhu, C., Shajahan, A., Azadi, P., Thomas, M. D., et al. (2020). Glycoengineering Tobacco Plants to Stably Express Recombinant Human Erythropoietin with Different $\mathrm{N}$-Glycan Profiles. Int. J. Biol. Macromolecules 157, 158-169. doi:10.1016/j.ijbiomac.2020.04.199

Koprivova, A., Stemmer, C., Altmann, F., Hoffmann, A., Kopriva, S., Gorr, G., et al. (2004). Targeted Knockouts of Physcomitrella Lacking Plant-specific Immunogenic N-Glycans. Plant Biotechnol. J. 2, 517-523. doi:10.1111/j. 1467-7652.2004.00100.x 
Kriechbaum, R., Ziaee, E., Grünwald-Gruber, C., Buscaill, P., Hoorn, R. A. L., and Castilho, A. (2020). BGAL1 Depletion Boosts the Level of $\beta$-galactosylation of $N$ - and O-glycans in N. benthamiana. Plant Biotechnol. J. 18, 1537-1549. doi:10. $1111 /$ pbi.13316

Laursen, T., Stonebloom, S. H., Pidatala, V. R., Birdseye, D. S., Clausen, M. H., Mortimer, J. C., et al. (2018). Bifunctional Glycosyltransferases Catalyze Both Extension and Termination of Pectic Galactan Oligosaccharides. Plant J. 94, 340-351. doi:10.1111/tpj.13860

Lee, K. J. D., Sakata, Y., Mau, S.-L., Pettolino, F., Bacic, A., Quatrano, R. S., et al. (2005). Arabinogalactan Proteins Are Required for Apical Cell Extension in the Moss Physcomitrella Patens. Plant Cell 17, 3051-3065. doi:10.1105/tpc.105. 034413

Leonard, R., Petersen, B. O., Himly, M., Kaar, W., Wopfner, N., Kolarich, D., et al. (2005). Two Novel Types of O-Glycans on the Mugwort Pollen Allergen Art V 1 and Their Role in Antibody Binding. J. Biol. Chem. 280, 7932-7940. doi:10. 1074/jbc.M410407200

Léonard, R., Wopfner, N., Pabst, M., Stadlmann, J., Petersen, B. O., Duus Ø, J. Ø., et al. (2010). A New Allergen from Ragweed (Ambrosia artemisiifolia) with Homology to Art V 1 from Mugwort. J. Biol. Chem. 285, 27192-27200. doi:10. 1074/jbc.M110.127118

Li, H., and d'Anjou, M. (2009). Pharmacological Significance of Glycosylation in Therapeutic Proteins. Curr. Opin. Biotechnol. 20, 678-684. doi:10.1016/j. copbio.2009.10.009

Ma, J. K.-C., Drossard, J., Lewis, D., Altmann, F., Boyle, J., Christou, P., et al. (2015). Regulatory Approval and a First-In-Human Phase I Clinical Trial of a Monoclonal Antibody Produced in Transgenic Tobacco Plants. Plant Biotechnol. J. 13, 1106-1120. doi:10.1111/pbi.12416

Mercx, S., Smargiasso, N., Chaumont, F., De Pauw, E., Boutry, M., and Navarre, C. (2017). Inactivation of the $\beta(1,2)$-xylosyltransferase and the $\alpha(1,3)$ fucosyltransferase Genes in Nicotiana tabacum BY-2 Cells by a Multiplex CRISPR/Cas9 Strategy Results in Glycoproteins without Plant-specific Glycans. Front. Plant Sci. 8, 403. doi:10.3389/fpls.2017.00403

Michelfelder, S., Parsons, J., Bohlender, L. L., Hoernstein, S. N. W., Niederkrüger, H., Busch, A., et al. (2017). Moss-produced, Glycosylation-optimized Human Factor H for Therapeutic Application in Complement Disorders. J. Am. Soc. Nephrol. 28, 1462-1474. doi:10.1681/asn.2015070745

Misaki, R., Kimura, Y., Palacpac, N. Q., Yoshida, S., Fujiyama, K., and Seki, T. (2003). Plant Cultured Cells Expressing Human Beta1,4-Galactosyltransferase Secrete Glycoproteins with Galactose-extended N-linked Glycans. Glycobiology 13, 199-205. doi:10.1093/glycob/cwg021

Mócsai, R., Blaukopf, M., Svehla, E., Kosma, P., and Altmann, F. (2020). The $\mathrm{N}$-Glycans of Chlorella sorokiniana and a Related Strain Contain Arabinose but Have Strikingly Different Structures. Glycobiology 30, 663-676. doi:10.1093/ glycob/cwaa012

Montero-Morales, L., and Steinkellner, H. (2018). Advanced Plant-based Glycan Engineering. Front. Bioeng. Biotechnol. 6, 81. doi:10.3389/fbioe.2018.00081

Padler-Karavani, V., Hurtado-Ziola, N., Pu, M., Yu, H., Huang, S., Muthana, S., et al. (2011). Human Xeno-autoantibodies against a Non-human Sialic Acid Serve as Novel Serum Biomarkers and Immunotherapeutics in Cancer. Cancer Res. 71, 3352-3363. doi:10.1158/0008-5472.CAN-10-4102

Palacpac, N. Q., Yoshida, S., Sakai, H., Kimura, Y., Fujiyama, K., Yoshida, T., et al. (1999). Stable Expression of Human 1,4-galactosyltransferase in Plant Cells Modifies N-linked Glycosylation Patterns. Proc. Natl. Acad. Sci. U.S.A. 96, 4692-4697. doi:10.1073/pnas.96.8.4692

Parsons, J., Altmann, F., Arrenberg, C. K., Koprivova, A., Beike, A. K., Stemmer, C., et al. (2012). Moss-based Production of Asialo-Erythropoietin Devoid of Lewis A and Other Plant-typical Carbohydrate Determinants. Plant Biotechnol. J. 10, 851-861. doi:10.1111/j.1467-7652.2012.00704.x

Parsons, J., Altmann, F., Graf, M., Stadlmann, J., Reski, R., and Decker, E. L. (2013). A Gene Responsible for Prolyl-hydroxylation of Moss-produced Recombinant Human Erythropoietin. Sci. Rep. 3, 3019. doi:10.1038/srep03019

Peng, B., Kong, G., Yang, C., and Ming, Y. (2020). Erythropoietin and its Derivatives: From Tissue Protection to Immune Regulation. Cell Death Dis. 11, 1-12. doi:10.1038/s41419-020-2276-8

Perez-Riverol, Y., Csordas, A., Bai, J., Bernal-Llinares, M., Hewapathirana, S., Kundu, D. J., et al. (2019). The PRIDE Database and Related Tools and Resources in 2019: Improving Support for Quantification Data. Nucleic Acids Res. 47, D442-D450. doi:10.1093/nar/gky1106
Petersen, B. L., MacAlister, C. A., and Ulvskov, P. (2021). Plant Protein O-Arabinosylation. Front. Plant Sci. 12, 400. doi:10.3389/fpls.2021.645219

Ponndorf, D., Meshcheriakova, Y., Thuenemann, E. C., Dobon Alonso, A., Overman, R., Holton, N., et al. (2021). Plant-made Dengue Virus-like Particles Produced by Co-expression of Structural and Non-structural Proteins Induce a Humoral Immune Response in Mice. Plant Biotechnol. J. 19, 745-756. doi:10.1111/pbi.13501

Reski, R., Bae, H., and Simonsen, H. T. (2018). Physcomitrella patens, a Versatile Synthetic Biology Chassis. Plant Cell Rep. 37, 1409-1417. doi:10.1007/s00299018-2293-6

Reski, R., Parsons, J., and Decker, E. L. (2015). Moss-made Pharmaceuticals: From Bench to Bedside. Plant Biotechnol. J. 13, 1191-1198. doi:10.1111/pbi.12401

Ropartz, D., and Ralet, M.-C. (2020). "Pectin Structure," in Pectin: Technological and Physiological Properties. Editor V. Kontogiorgos (Manhattan, NY: Springer International Publishing), 17-36. doi:10.1007/978-3-030-53421-9_2

Ruiz-Molina, N., Parsons, J., Müller, M., Hoernstein, S. N. W., Bohlender, L. L., Pumple, S., et al. (2021). A Synthetic Protein as Efficient Multitarget Regulator against Complement Over-activation. bioRxiv. doi:10.1101/2021.04.27.441647

Schneider, J., Castilho, A., Pabst, M., Altmann, F., Gruber, C., Strasser, R., et al. (2015). Characterization of Plants Expressing the Human $\beta 1,4-$ galactosyltrasferase Gene. Plant Physiol. Biochem. 92, 39-47. doi:10.1016/j. plaphy.2015.04.010

Schoberer, J., and Strasser, R. (2011). Sub-compartmental Organization of Golgiresident $\mathrm{N}$-Glycan Processing Enzymes in Plants. Mol. Plant 4, 220-228. doi:10. $1093 / \mathrm{mp} / \mathrm{ssq} 082$

Seifert, G. J., Strasser, R., and Van Damme, E. J. M. (2021). Editorial: Plant Glycobiology - a Sweet World of Glycans, Glycoproteins, Glycolipids, and Carbohydrate-binding Proteins. Front. Plant Sci. 12, 1869. doi:10.3389/fpls. 2021.751923

Shen, J.-S., Busch, A., Day, T. S., Meng, X.-L., Yu, C. I., Dabrowska-Schlepp, P., et al. (2016). Mannose Receptor-mediated Delivery of Moss-made agalactosidase A Efficiently Corrects Enzyme Deficiency in Fabry Mice. J. Inherit. Metab. Dis. 39, 293-303. doi:10.1007/s10545-015-9886-9

Shin, Y.-J., Chong, Y.-J., Yang, M.-S., and Kwon, T.-H. (2011). Production of Recombinant Human Granulocyte Macrophage-colony Stimulating Factor in rice Cell Suspension Culture with a Human-like N-Glycan Structure. Plant Biotechnol. J. 9, 1109-1119. doi:10.1111/j.1467-7652.2011.00636.x

Showalter, A. M., and Basu, D. (2016). Extensin and Arabinogalactan-Protein Biosynthesis: Glycosyltransferases, Research Challenges, and Biosensors. Front. Plant Sci. 7, 814. doi:10.3389/fpls.2016.00814

Solá, R. J., and Griebenow, K. (2010). Glycosylation of Therapeutic Proteins. BioDrugs 24, 9-21. doi:10.2165/11530550-000000000-00000

Sourrouille, C., Marquet-Blouin, E., D’Aoust, M.-A., Kiefer-Meyer, M.-C., Seveno, M., Pagny-Salehabadi, S., et al. (2008). Down-regulated Expression of Plantspecific Glycoepitopes in Alfalfa. Plant Biotechnol. J. 6, 702-721. doi:10.1111/j. 1467-7652.2008.00353.x

Steffan, W., Kovácč, P., Albersheim, P., Darvill, A. G., and Hahn, M. G. (1995). Characterization of a Monoclonal Antibody that Recognizes an Arabinosylated $(1 \rightarrow 6)-\beta-D-G a l a c t a n$ Epitope in Plant Complex Carbohydrates. Carbohydr. Res. 275, 295-307. doi:10.1016/0008-6215(95)00174-r

Stenitzer, D., Mócsai, R., Zechmeister, H., Reski, R., Decker, E. L., and Altmann, F. (2022). O-methylated N-Glycans Distinguish Mosses from Vascular Plants. Biomolecules 12, 136. doi:10.3390/biom12010136

Strasser, R., Altmann, F., Mach, L., Glössl, J., and Steinkellner, H. (2004). Generation of Arabidopsis thaliana Plants with Complex N-glycans Lacking $\beta 1,2$-linked Xylose and Core a1,3-linked Fucose. FEBS Lett. 561, 132-136. doi:10.1016/S0014-5793(04)00150-4

Strasser, R., Castilho, A., Stadlmann, J., Kunert, R., Quendler, H., Gattinger, P., et al. (2009). Improved Virus Neutralization by Plant-produced Anti-HIV Antibodies with a Homogeneous $\beta 1,4$-galactosylated $N$-Glycan Profile. J. Biol. Chem. 284, 20479-20485. doi:10.1074/jbc.M109.014126

Strasser, R., Stadlmann, J., Schähs, M., Stiegler, G., Quendler, H., Mach, L., et al. (2008). Generation of Glyco-engineered Nicotiana benthamiana for the Production of Monoclonal Antibodies with a Homogeneous Human-like N-Glycan Structure. Plant Biotechnol. J. 6, 392-402. doi:10.1111/j.1467-7652. 2008.00330.x

Strepp, R., Scholz, S., Kruse, S., Speth, V., and Reski, R. (1998). Plant Nuclear Gene Knockout Reveals a Role in Plastid Division for the Homolog of the Bacterial 
Cell Division Protein FtsZ, an Ancestral Tubulin. Proc. Natl. Acad. Sci. U.S.A. 95, 4368-4373. doi:10.1073/pnas.95.8.4368

Suga, A., Nagae, M., and Yamaguchi, Y. (2018). Analysis of Protein Landscapes Around $N$-Glycosylation Sites from the PDB Repository for Understanding the Structural Basis of $\mathrm{N}$-Glycoprotein Processing and Maturation. Glycobiology 28, 774-785. doi:10.1093/glycob/cwy059

Tan, H., Su, W., Zhang, W., Wang, P., Sattler, M., and Zou, P. (2019). Recent Advances in Half-life Extension Strategies for Therapeutic Peptides and Proteins. Curr. Pharm. Des. 24, 4932-4946. doi:10.2174/ 1381612825666190206105232

Tangvoranuntakul, P., Gagneux, P., Diaz, S., Bardor, M., Varki, N., Varki, A., et al. (2003). Human Uptake and Incorporation of an Immunogenic Nonhuman Dietary Sialic Acid. Proc. Natl. Acad. Sci. U.S.A. 100, 12045-12050. doi:10.1073/ pnas. 2131556100

Thomann, M., Reckermann, K., Reusch, D., Prasser, J., and Tejada, M. L. (2016). Fc-galactosylation Modulates Antibody-dependent Cellular Cytotoxicity of Therapeutic Antibodies. Mol. Immunol. 73, 69-75. doi:10.1016/j.molimm. 2016.03.002

Top, O., Parsons, J., Bohlender, L. L., Michelfelder, S., Kopp, P., Busch-Steenberg, C., et al. (2019). Recombinant Production of MFHR1, a Novel Synthetic Multitarget Complement Inhibitor, in Moss Bioreactors. Front. Plant Sci. 10, 260. doi:10.3389/fpls.2019.00260

Tourdot, S., and Hickling, T. P. (2019). Nonclinical Immunogenicity Risk Assessment of Therapeutic Proteins. Bioanalysis 11, 1631-1643. doi:10.4155/ bio-2018-0246

Tripathi, N. K., and Shrivastava, A. (2019). Recent Developments in Bioprocessing of Recombinant Proteins: Expression Hosts and Process Development. Front. Bioeng. Biotechnol. 7, 420. doi:10.3389/fbioe.2019.00420

Varki, A. (2001). Loss of N-Glycolylneuraminic Acid in Humans: Mechanisms, Consequences, and Implications for Hominid Evolution. Am. J. Phys. Anthropol. 116, 54-69. doi:10.1002/ajpa.10018

Walsh, G. (2018). Biopharmaceutical Benchmarks 2018. Nat. Biotechnol. 36, 1136-1145. doi:10.1038/nbt.4305

Wang, Q., Stuczynski, M., Gao, Y., and Betenbaugh, M. J. (2015). Strategies for Engineering Protein $\mathrm{N}$-Glycosylation Pathways in Mammalian Cells. Methods Mol. Biol. 1321, 287-305. doi:10.1007/978-1-4939-2760-9_20

Ward, B. J., Gobeil, P., Séguin, A., Atkins, J., Boulay, I., Charbonneau, P.-Y., et al. (2021). Phase 1 Randomized Trial of a Plant-Derived Virus-Like Particle Vaccine for COVID-19. Nat. Med. 27, 1071-1078. doi:10.1038/s41591-021-01370-1

Ward, B. J., Makarkov, A., Séguin, A., Pillet, S., Trépanier, S., Dhaliwall, J., et al. (2020). Efficacy, Immunogenicity, and Safety of a Plant-Derived, Quadrivalent,
Virus-like Particle Influenza Vaccine in Adults (18-64 Years) and Older Adults ( $\geq 65$ Years): Two Multicentre, Randomised Phase 3 Trials. The Lancet 396, 1491-1503. doi:10.1016/S0140-6736(20)32014-6

Weise, A., Altmann, F., Rodriguez-Franco, M., Sjoberg, E. R., Bäumer, W., Launhardt, H., et al. (2007). High-level Expression of Secreted Complex Glycosylated Recombinant Human Erythropoietin in the Physcomitrella Delta-Fuc-T Delta-Xyl-T Mutant. Plant Biotechnol. J 5, 389-401. doi:10. 1111/j.1467-7652.2007.00248.x

Welch, L. G., and Munro, S. (2019). A Tale of Short Tails, through Thick and Thin: Investigating the Sorting Mechanisms of Golgi Enzymes. FEBS Lett. 593, 2452-2465. doi:10.1002/1873-3468.13553

Wiedemann, G., van Gessel, N., van Köchl, F., Köchl, L., Schulze, K., Maloukh, L., et al. (2018). RecQ Helicases Function in Development, DNA Repair, and Gene Targeting in Physcomitrella patens. Plant Cell 30, 717-736. doi:10.1105/tpc.17. 00632

Wilson, I. B. H., Zeleny, R., Kolarich, D., Staudacher, E., Stroop, C. J. M., Kamerling, J. P., et al. (2001). Analysis of Asn-linked Glycans from Vegetable Foodstuffs: Widespread Occurrence of Lewis a, Core 1,3-linked Fucose and Xylose Substitutions. Glycobiology 11, 261-274. doi:10.1093/ glycob/11.4.261

Zhou, Q., and Qiu, H. (2019). The Mechanistic Impact of N-Glycosylation on Stability, Pharmacokinetics, and Immunogenicity of Therapeutic Proteins. J. Pharm. Sci. 108, 1366-1377. doi:10.1016/j.xphs.2018.11.029

Conflict of Interest: The authors declare that the research was conducted in the absence of any commercial or financial relationships that could be construed as a potential conflict of interest.

Publisher's Note: All claims expressed in this article are solely those of the authors and do not necessarily represent those of their affiliated organizations, or those of the publisher, the editors, and the reviewers. Any product that may be evaluated in this article, or claim that may be made by its manufacturer, is not guaranteed or endorsed by the publisher.

Copyright (c) 2022 Bohlender, Parsons, Hoernstein, Bangert, Rodríguez-Jahnke, Reski and Decker. This is an open-access article distributed under the terms of the Creative Commons Attribution License (CC BY). The use, distribution or reproduction in other forums is permitted, provided the original author(s) and the copyright owner(s) are credited and that the original publication in this journal is cited, in accordance with accepted academic practice. No use, distribution or reproduction is permitted which does not comply with these terms. 